\title{
An Unusual Presentation of Syringomyelia
}

\author{
${ }^{1}$ Arvind Varma, ${ }^{2}$ Alok Kumar Agrahari
}

\begin{abstract}
Sudden onset stridor due to bilateral vocal cord paralysis in an adult patient with undiagnosed syringomyelia as a sole presenting symptom is rare. Here we are presenting a case of a 40-year-old female with undiagnosed syringomyelia due to Chiari type I malformation presenting with sudden onset stridor. Even 1 year after decompression surgery, her vocal cord functions did not improve.
\end{abstract}

Keywords: Chiari type I malformation, Syringomyelia, Vocal cord paralysis.

How to cite this article: Varma A, Agrahari AK. An Unusual Presentation of Syringomyelia. Int J Phonosurg Laryngol 2016;6(1):40-41.

Source of support: Nil

Conflict of interest: None

\section{INTRODUCTION}

Syringomyelia is a developmental cavity of the cervical cord that is prone to enlarge and produce progressive myelopathy. Symptoms begin insidiously in adolescence or early adulthood, progress irregularly, and may undergo spontaneous arrest for several years. More than half of all cases of syringomyelia are associated with Chiari type I malformation in which the cerebellar tonsils protrude through the foramen magnum into the cervical spinal canal. Usual presentation is central cord syndrome consisting of dissociated sensory loss, which has cape-like distribution involving the nape of neck, shoulders, and upper arms. Extension of syrinx into the medulla causes palatal or vocal cord paralysis, dysarthria, nystagmus, episodic vertigo, and tongue weakness with atrophy. ${ }^{1}$

Vocal fold palsy is rarely the presenting complaint of an adult with syringomyelia or a Chiari malformation. ${ }^{2}$ In this article we describe a case of syringomyelia with syringobulbia and a Chiari type 1 malformation presenting with sole symptom of bilateral vocal cord palsy.

\footnotetext{
${ }^{1}$ Assistant Professor, ${ }^{2}$ Senior Resident

1,2Department of ENT, Shri Guru Ram Rai Institute of Medical and Health Sciences, Dehradun, Uttarakhand, India

Corresponding Author: Arvind Varma, Assistant Professor Department of ENT, Shri Guru Ram Rai Institute of Medical and Health Sciences, Dehradun, Uttarakhand, India, Phone: +919627786755, e-mail: drvarmaarvind@gmail.com
}

\section{CASE REPORT}

A 40-year-old female presented with sudden onset stridor of 2-hour duration in our department. There was history of upper respiratory tract infection for last 3 to 4 days. There was previous history of stridor of less severity 9 months ago, which was relieved on conservative management.

She had no history of trauma, severe neck manipulation or neck extension, or severe cough.

Laryngoscopic examination revealed bilateral vocal cord paralysis. Palatal reflex was diminished.

An urgent tracheostomy was done after which patient was relieved of her symptoms.

The patient was investigated for cause of vocal cord paralysis in which Brain MRI and magnetic resonance myelogram showed basilar invagination, atlantooccipital and C2-C3 vertebral fusion, platybasia, and Arnold-Chiari malformation type I with holocord syringohydromyelia (Figs 1 and 2).

The patient underwent posterior fossa decompression by neurosurigical team. After a 3-month follow-up there was no improvement in vocal cord mobility. Even after 1 year there was no improvement in mobility of vocal cords.

\section{DISCUSSION}

The word "syringomyelia" means reed- or flute-like spinal cord.

Syringomyelia is a pathologic cystic cavity within the spinal cord containing cerebrospinal fluid. It is most

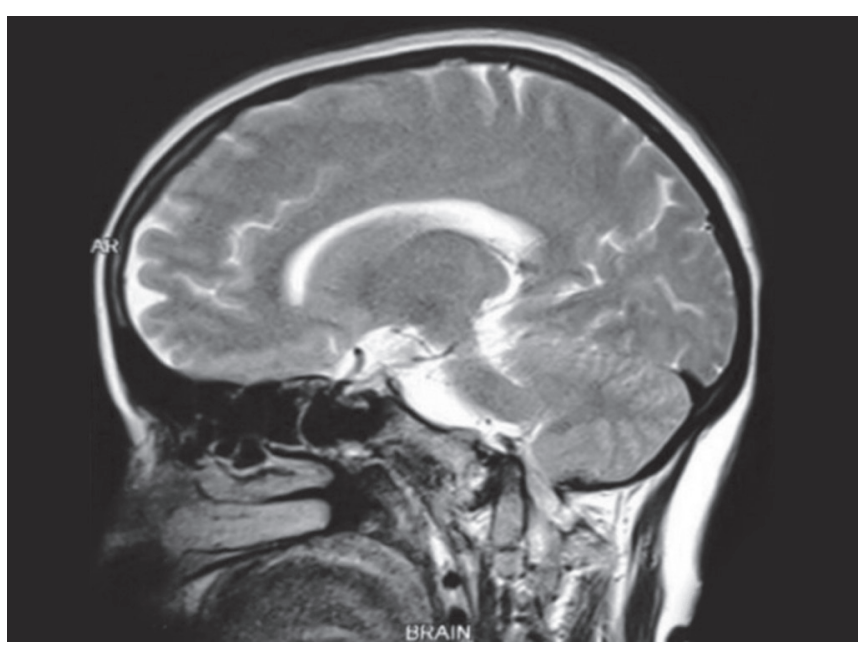

Fig. 1: T2 sagittal image of brain with odontoid peg measuring $13 \mathrm{~mm}$ above Chamberlain's line suggestive of basilar invagination 


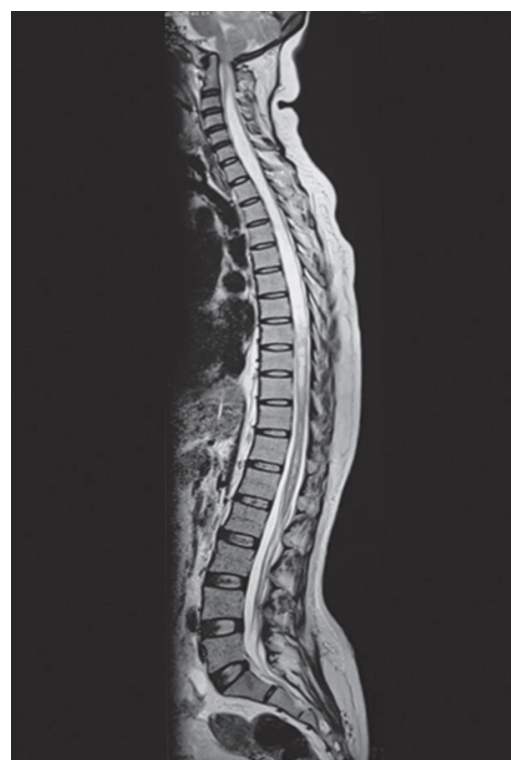

Fig. 2: T2 sagittal image of whole spine showing syringomyelia. The maximum diameter is approximately $1 \mathrm{~cm}$ at $\mathrm{C} 5$ level

commonly seen as a complication of a Chiari type I malformation, which is the caudal herniation of the cerebellar tonsils through the foramen magnum and into the cervical spinal canal. ${ }^{3}$

The disease affects all races and both genders, although with slight predominance in women.

Although most researchers consider the average age at presentation is approximately 35 years, symptoms onset can occur at any age, from 1 year to older than $60 .{ }^{4}$

Syringomyelia commonly presents with progressive weakness in arms and legs along with stiffness in the back, shoulders, arms, or legs. Rare reported presentations of syringomyelia include progressive vocal fold paralysis ${ }^{5}$ and acute respiratory failure. ${ }^{6}$

Symptoms may vary between periods of exacerbation and remission.

Bilateral vocal cord paralysis has been rarely reported as a result of Chiari malformation, and the majority of reports have been observed in the pediatric population.

Chiari malformation is a rare cause of sudden onset bilateral vocal cord paralysis in the adult population.
Posterolateral extension of the syrinx into the medulla oblongata often involves the nucleus ambiguus and can cause paresis of the soft palate, pharynx, and vocal folds and occasionally cause laryngeal stridor.

Involvement of the dorsal motor nuclei of the vagus nerve can also produce episodic stridor and laryngospasm, whereas lesions that destroy the nuclei ambigui are associated with chronic stridor or vocal fold paralysis.

Symptoms may be reversible by reducing intracranial pressure. However, the amount of improvement depends on the extent of neurological damage sustained prior to the decompression, and the improvement in vocal cord mobility may not occur despite decompression surgery. ${ }^{5}$

\section{CONCLUSION}

In cases of sudden onset vocal cord paralysis in adults, we should keep in mind the remote possibility syringomyelia with Chiari type I malformation and investigate accordingly.

\section{REFERENCES}

1. Hauser SL, Ropper AH. Diseases of the spinal cord. In: Longo DL, Kasper DL, Jameson JL, Anthony SF, Stephen LH, Joseph L, editors. Harrison's principle of internal medicine. 18th ed. New York: McGraw Hill; 2012. p. 3373-3374.

2. Abraham-Igwe C, Ahmad I, O'Connell J, Chavda SV. Syringomyelia and bilateral vocal fold palsy. J Laryngol Otol 2002 Aug;116(8):633-636.

3. Banerji NK, Millar JH. Chiari malformation presenting in adult life. Its relationship with syringomyelia. Brain 1974 Mar;97(1):157-168.

4. Fernández AA, Guerrero AI, Martínez MI, Vázquez ME, Fernández JB, Chesa i Octavio E, Labrado Jde L, Silva ME, de Araoz MF, García-Ramos R, et al. Malformations of the craniocervical junction (Chiari type I and syringomyelia: classification, diagnosis and treatment). BMC Musculoskelet Disord 2009 Dec 17;10 (Suppl 1):S1.

5. Viswanatha B. Syringomyelia with syringobulbia presenting as vocal fold paralysis. Ear Nose Throat J 2009 Jul;88(7):E20.

6. Al Bashapshe A, Bhatia H, Aziz S. Acute respiratory failure as a first manifestation of syringomyelia. Lung India 2010 Apr;27(2):93-95. 